\title{
Impairment of adult hippocampal neural progenitor proliferation by methamphetamine: role for nitrotyrosination
}

\author{
Arun Venkatesan ${ }^{1 *}$, Lerna Uzasci ${ }^{2,3}$, Zhaohui Chen², Labchan Rajbhandari', Carol Anderson ${ }^{1,7}$, Myoung-Hwa Lee ${ }^{1,7}$, \\ Mario A Bianchet ${ }^{4}$, Robert Cotter ${ }^{2,3}$, Hongjun Song ${ }^{1,5,6}$ and Avindra Nath ${ }^{1,6,7}$
}

\begin{abstract}
Methamphetamine (METH) abuse has reached epidemic proportions, and it has become increasingly recognized that abusers suffer from a wide range of neurocognitive deficits. Much previous work has focused on the deleterious effects of METH on mature neurons, but little is known about the effects of METH on neural progenitor cells (NPCs). It is now well established that new neurons are continuously generated from NPCs in the adult hippocampus, and accumulating evidence suggests important roles for these neurons in hippocampal-dependent cognitive functions. In a rat hippocampal NPC culture system, we find that METH results in a dose-dependent reduction of NPC proliferation, and higher concentrations of METH impair NPC survival. NPC differentiation, however, is not affected by METH, suggesting cell-stage specificity of the effects of METH. We demonstrate that the effects of METH on NPCs are, in part, mediated through oxidative and nitrosative stress. Further, we identify seventeen NPC proteins that are post-translationally modified via 3-nitrotyrosination in response to METH, using mass spectrometric approaches. One such protein was pyruvate kinase isoform M2 (PKM2), an important mediator of cellular energetics and proliferation. We identify sites of PKM2 that undergo nitrotyrosination, and demonstrate that nitration of the protein impairs its activity. Thus, METH abuse may result in impaired adult hippocampal neurogenesis, and effects on NPCs may be mediated by protein nitration. Our study has implications for the development of novel therapeutic approaches for METH-abusing individuals with neurologic dysfunction and may be applicable to other neurodegenerative diseases in which hippocampal neurogenesis is impaired.
\end{abstract}

\section{Background}

Over 35 million people internationally abuse METH, and in the United States METH abuse has reached epidemic proportions. Through mechanisms that are not yet well understood, METH abusers suffer from a variety of neurocognitive deficits, including behavioral changes, executive dysfunction, deficits in perceptual speed and information manipulation, and impairment of verbal and spatial memory. Neurocognitive deficits may persist after cessation of METH abuse, are slow to improve, and may not completely reverse [1-5]. Although METH was initially thought to selectively damage monoaminergic nerve terminals, recent studies have consistently shown that widespread

\footnotetext{
* Correspondence: avenkat2@jhmi.edu

'Department of Neurology, Johns Hopkins University School of Medicine, 600 N. Wolfe St., Baltimore, MD 21287, USA

Full list of author information is available at the end of the article
}

neuronal cell death results [6-10]. Cell death involves not only the striatum and cortex, but the hippocampus as well $[7,11]$. Although the molecular mechanisms underlying METH neurotoxicity are likely multifactorial, several key findings support a significant role for both oxidative and nitrosative stress. Mice overexpressing superoxide dismutase, an antioxidant, show markedly decreased METHinduced apoptosis [12]. Suppression of nitric oxide (NO) production, through both pharmacologic and genetic means, also protects against METH-mediated neurotoxicity. In addition, METH causes increased levels of 3-nitrotyrosine adduct formation, reflective of oxidative and nitrosative stress [13,14]. Although METH-induced oxidative and nitrosative stress and toxicity have been demonstrated in neurons, little is known about whether other cells within the brain, such as NPCs, are similarly affected by METH.

\section{() Biomed Central}


The brains of mammals contain several distinct populations of cells that are capable of dividing and differentiating into neurons and glial cells throughout adulthood $[15,16]$. Increasing evidence suggests that continued neurogenesis is important for maintenance of cognitive function [17-20]. Within the hippocampal dentate gyrus (DG), neurogenesis occurs in the subgranular zone and granule cell layer. New neurons formed here are functionally incorporated into the hippocampus [21] and may participate in the formation of hippocampal-dependent memory [22].

Studies in rodents have demonstrated that hippocampal neural progenitor cells (NPCs) can respond to a wide variety of environmental demands, such as enrichment and exercise, by increasing neurogenesis, with consequent enhancement in long-term potentiation of synaptic transmission as well as functional learning and memory [23-25]. On the other hand, neurogenesis is decreased in many settings in which learning and memory are disrupted in rodents, including aging, stress, inflammation, and exposure to certain drugs [16,26-29]. Of note, certain pathogenic conditions, such as epilepsy and stroke, lead to increased neurogenesis without a measurable improvement in cognition, possibly due to abnormal migration and integration of newly formed neurons [30]. Thus, pathogenic processes that either increase or decrease neurogenesis may interfere with cognitive function.

Although several drugs of abuse have been shown to influence neurogenesis [31,32], limited data are available with respect to the effects of METH. Several in vivo models of METH exposure have demonstrated decreases in hippocampal neurogenesis [33-35]. In addition, a recent study demonstrated that METH induces NPC death through mitochondrial fragmentation [36]. However, cellular and molecular mechanisms by which METH affects NPCs remain largely unknown. Here, we investigate mechanisms by which METH-induced oxidative and nitrosative stress impair NPC function.

\section{Results}

\section{Characterization of cultures of adult hippocampal progenitor cells}

NPCs were isolated from hippocampi of adult rats and maintained in culture media containing fibroblast growth factor (FGF) to ensure proliferation of these cells. Under these conditions, $>99 \%$ of cells immunostained with antibody to nestin, a marker for NPCs (Figure 1A). These cells also stained for Ki67 a marker of proliferating cells (Figure 1A). To determine if these cells could be differentiated into various neural cell types, we initially treated them with BrdU to label the dividing cells and then changed the media to one containing fetal bovine serum (FBS) and retinoic acid (RA). Under these conditions, we found the presence of neuronal cells as demonstrated by immunostaining for Tuj1 (Figures $1 \mathrm{~B}$ and $1 \mathrm{C}$ ), astrocytes that immunostained for GFAP (Figure 1C) and oligodendrocytes that immunostained for RIP (Figure 1B). Nearly equal numbers (15-20\%) of each of the cell types were present (Figure 1D). The remainder were undifferentiated NPCs. These self-renewing AHP thus fulfilled the definition of multipotent NPCs and were used for all further experiments.

\section{METH impairs proliferation and survival of NPCs}

To determine the effect of METH on proliferation of NPCs, these cells were exposed to METH for 24 or 48 hours, and then pulsed with BrdU for 4 hours. METH exposure resulted in a decrease in BrdU positive cells in both a dose- and time-dependent manner with significant effects at $>100 \mathrm{uM} \mathrm{METH}$ (Figure 2A). After 48 hours at the highest concentration of METH used, only 25\% of cells showed BrdU uptake.

We next considered that METH may directly cause NPC death, thus accounting for the reduction in proliferating NPCs. NPCs were exposed to METH for 24 to 72 hours, and cell death was quantified using several measures. Trypan blue staining demonstrated that METH caused a dose- and time-dependent increase in cell death (Figure 2B). Doses of $>250 \mathrm{uM}$, resulted in significantly increased cell death. As opposed to BrdU uptake, dosages of $100 \mathrm{uM} \mathrm{METH}$ did not cause an increase in cell death even at 72 hours post treatment. At the highest concentration of METH, $50 \%$ cell death was seen at 72 hours (Figure 2B). Effects of METH on NPC death were also confirmed by 7 -aminoactinomycin D (7-AAD) staining followed by flow cytometry. The amounts of dead cells determined by both techniques were similar (data not shown). To determine if METH could induce cell death via apoptosis, a TdT-mediated dUTP nick end-labeling (TUNEL) assay was performed. Exposure of NPCs to METH at doses of $250 \mathrm{uM}, 500 \mathrm{uM}$ (not shown) and $1 \mathrm{mM}$ (Figure 2C) resulted in TUNEL positive cells, consistent with apoptotic DNA fragmentation.

\section{METH does not affect initial NPC differentiation}

We considered the possibility that a reduction in proliferating NPCs upon exposure to METH may occur due to an increased drive toward differentiation. To investigate whether METH causes premature differentiation, we exposed proliferating NPCs to METH for 24 hours, and immunostained cells with markers of differentiating cells 4 days later. METH exposure did not result in premature differentiation of proliferating NPCs into neurons, astrocytes, or oligodendrocytes (Figure 3A), although total numbers of differentiated cells were reduced (Figure 3B). These results indicate that METH does not promote premature differentiation of proliferating NPCs. To further 


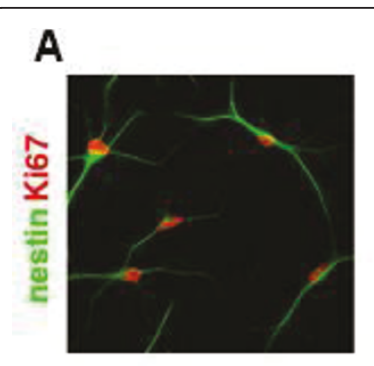

FGF-2 (Proliferation)
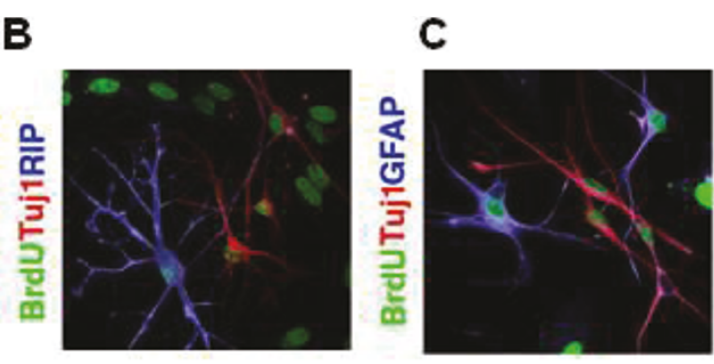

FBS + RA (Differentiation)

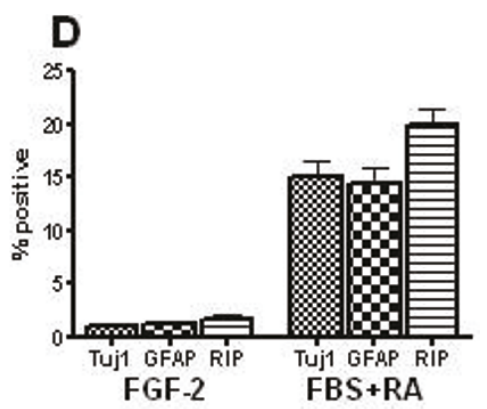

FGF-2

Figure 1 Establishment of NPC culture system in vitro. Adult hippocampal progenitors (NPCs) derived from Fisher rats were maintained under either proliferative or differentiating conditions. A. Under proliferative conditions, over $99 \%$ of cells are co-labeled with antibodies to nestin (green, cytoplasmic) and Ki67 (red, nuclear), markers of proliferating cells. B,C. Cells are exposed to proliferative conditions for 24 hrs in the presence of BrdU, followed by 5 days of differentiation conditions stain for BrdU (green), indicating that they were all initially proliferating cells. In addition, some cells in B co-label with Tuj1 (red, neuron), or RIP (blue, oligodendrocyte) and in C co-label with GFAP (blue, astrocyte). D. Immunostaining of cells derived from clonal NPCs grown under proliferative (FGF-2) or differentiating (FBS+RA) conditions yields reproducible percentages of Tuj1 (neuronal), GFAP (astrocytic), and RIP (oligodendroglial) positive cells.

determine whether METH affects NPC differentiation, we treated proliferating NPCs with METH, followed by culture under differentiating conditions. Under these conditions, NPCs differentiated into neurons, astrocytes, and oligodendrocytes with the same frequency when exposed to METH as compared to control conditions (Figure 3C). Again, fewer differentiated cells were present in the METH-treated group as compared to controls (Figure 3D). Finally, we determined the effects of METH exposure on NPCs after the onset of differentiation. Under these conditions, too, METH did not significantly affect the frequencies of differentiating cells (Figure 3E). Interestingly, there was no reduction in total numbers of differentiated cells in the METH group as compared to control, suggesting that proliferating NPCs may be preferentially susceptible to the effects of METH as compared to differentiating NPCs.

\section{METH induces oxidative and nitrosative stress in NPCs}

We determined whether the effects of METH on NPC proliferation and viability may be due to induction of oxidative and nitrosative stress. We first exposed NPCs to METH and measured intracellular reactive oxygen species using the fluorescent dye DCFDA. At concentrations of $>100 \mathrm{uM}, \mathrm{METH}$ caused marked increases in DCFDA fluorescence at both 4 hours (Figure 4A) and 24 hours (not shown). To investigate nitrosative stress induced by METH, we assessed nitric oxide production, which has recently been shown to occur endogenously in hippocampal NPCs [37]. We employed the Griess reaction to measure nitrite formation, which occurs following the generation of nitric oxide. METH treatment resulted in nitrite formation in a dose-dependent fashion at $24 \mathrm{hrs}$ (Figure 4B). To investigate the consequences of nitrosative and oxidative stress, we measured the formation of nitrotyrosine adducts on NPC proteins. 3-nitrotyrosination represents a common final pathway for the effects of both oxidative and nitrosative stress [38]. Semiquantitative analysis of 3-nitrotyrosine slot blots demonstrated that METH causes a dose-dependent increase in total 3nitrotyrosination (Figure 4C). At concentrations of $>250$ uM METH, levels of nitrotyrosination were similar to those achieved by exposure to several potent inducers of oxidative stress. Western blotting analysis revealed that nitrotyrosination of several NPC proteins was increased in response to METH (Figure 4D). In particular, nitrotyrosination of proteins of approximate molecular masses $90 \mathrm{kDa}, 45 \mathrm{kDa}, 32 \mathrm{kDa}, 30 \mathrm{kDa}$, and $25 \mathrm{kDa}$ (black arrows) was increased by both METH and staurosporine (STS), an inducer of oxidative stress. Other proteins, such as those of approximate molecular mass $57 \mathrm{kDa}$ (p57) and $62 \mathrm{kDa}$ (p62) (red arrows), appeared not to be significantly nitrotyrosinated under control conditions, but were after METH exposure. Of note, differences in nitrotyrosination were found between STS- and METHexposed NPCs; the protein of apparent molecular mass $30 \mathrm{kDa}$, for example, appears to be more strongly nitrotyrosinated upon METH exposure, while the protein of apparent mass $10 \mathrm{kDa}$ appears more strongly nitrotyrosinated upon STS exposure.

We next determined if compounds such as Trolox, a water-soluble analog of Vitamin E, and uric acid (UA), that have broad antioxidant activity could block the effects of METH on NPCs. As shown in figure 5A, both Trolox (10uM) and UA (250uM) resulted in marked decreases in nitrotyrosination of many NPC proteins. A lower dose of UA (25uM), did not decrease METHinduced oxidative stress in NPCs. Further, METH-treated NPC viability was increased by both Trolox and UA (Figure 5B), indicating that antioxidants can confer 


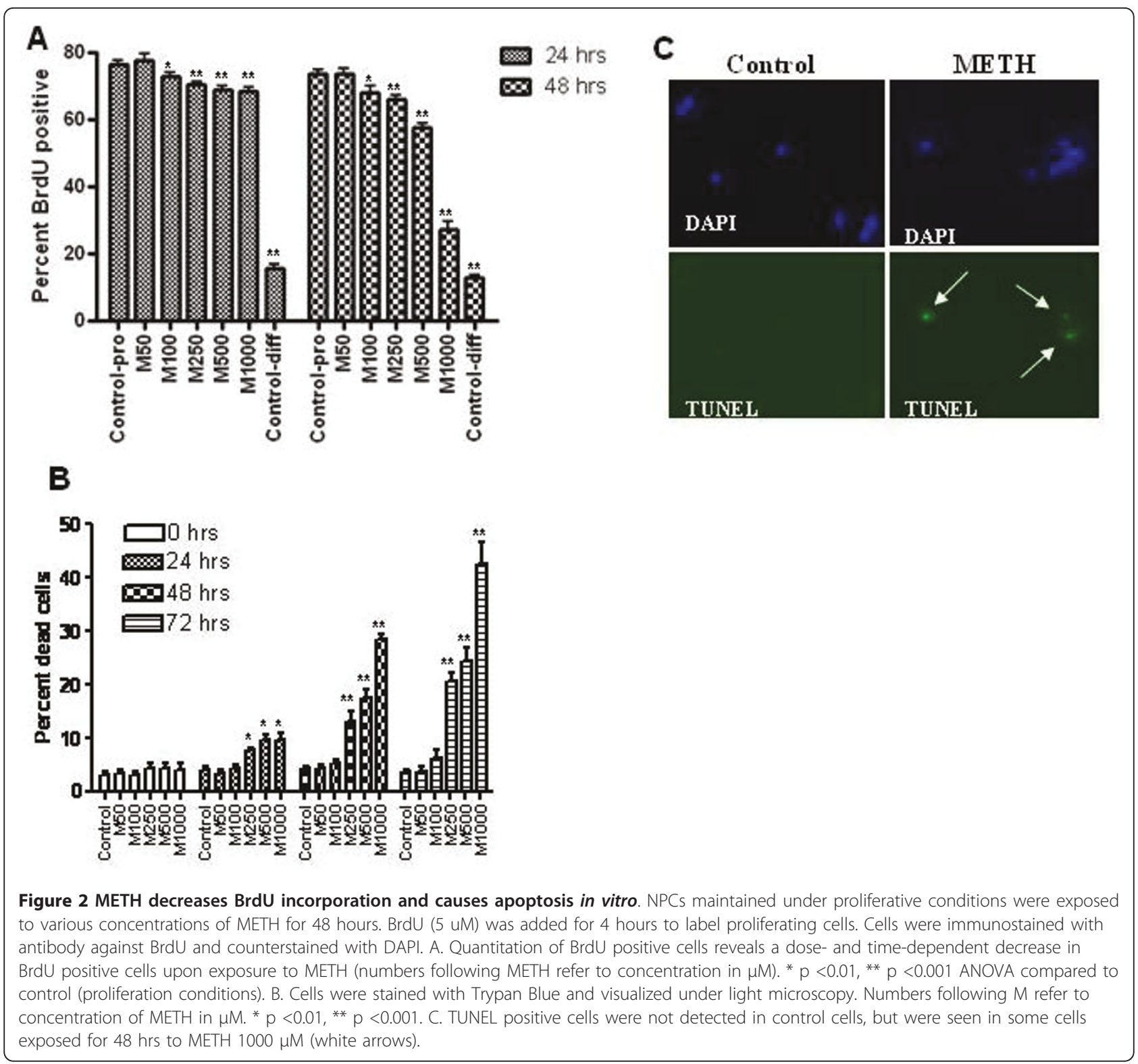

partial protection against METH-induced NPC death. Importantly, the lower dose of UA (25uM), which did not decrease nitrotyrosination, also did not protect against METH-induced AHP cell death.

METH leads to nitrotyrosination and decreased activity of PKM2 in NPCs

To identify individual NPC proteins that may be nitrated in response to METH treatment, we immunoprecipitated METH-treated lysates with antibody to 3-nitrotyrosine. Captured proteins were eluted, trypsinized, and analyzed by mass spectrometry; the resultant peptides and their proteins were identified using commercial database searching programs. In our experiments, the additional gel separation and gel extraction steps resulted in some sample loss and low sequence coverage, which was sufficient for identification of the proteins but not the specific observation of the nitrated peptides. Seventeen proteins were identified in 3-NT immunoprecipitated METHtreated NPCs that were not observed in untreated NPCs, including pyruvate kinase M2 (Table 1).

Since we found that METH preferentially acts on proliferating NPCs, we next sought to confirm nitrotyrosination of pyruvate kinase M2 (PKM2), a protein that mediates cell proliferation. Western blot analysis demonstrated that PKM2 is expressed in proliferating NPCs, but not in terminally differentiated cultured neurons (data not shown). We immunoprecipitated METH-treated NPC lysates with 

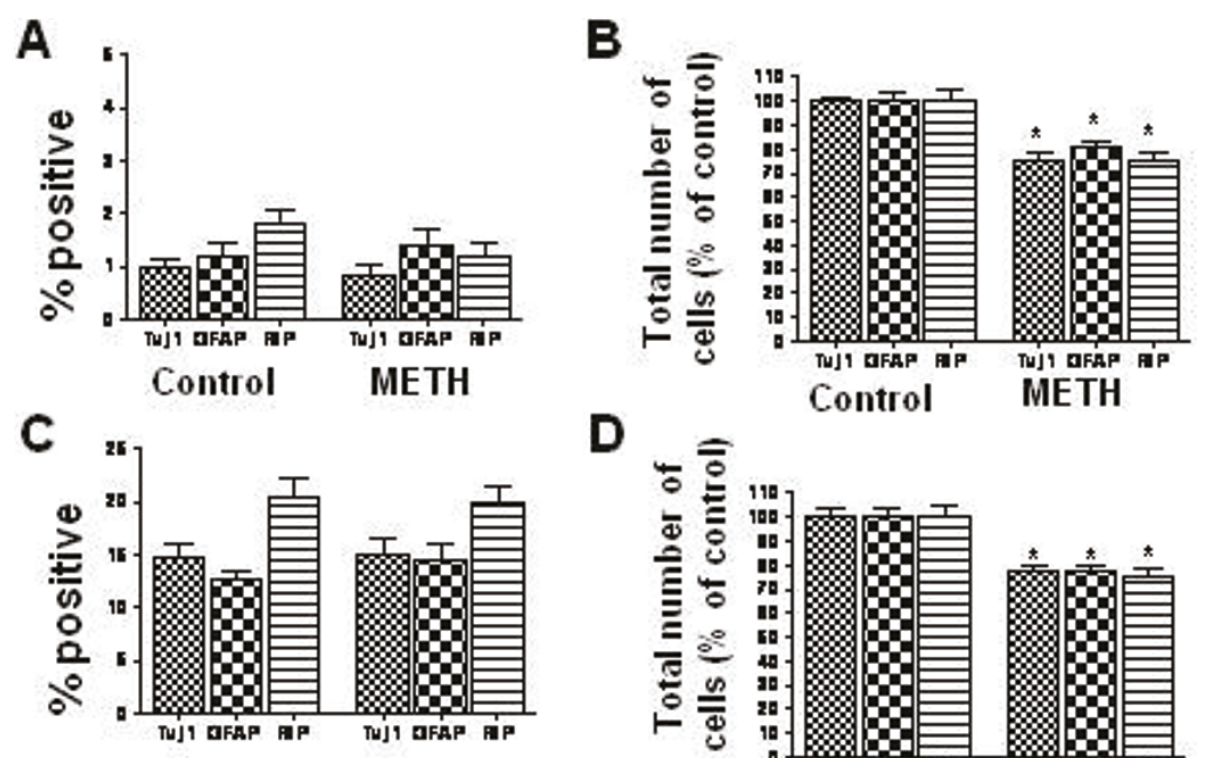

Control
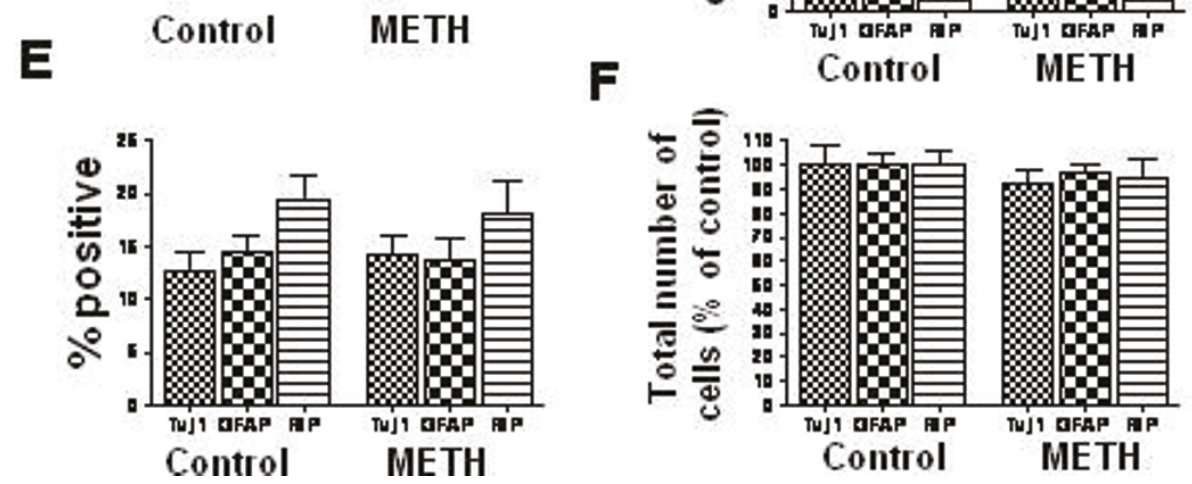

Figure 3 METH does not affect differentiation of NPCs. A,B. NPCs maintained under proliferative conditions were exposed to METH (250 UM) for 24 hours, and fixed and immunostained 4 days later with antibody against Tuj1, GFAP, and RIP, and counterstained with DAPI. METH treatment does not result in premature differentiation (A), but does result in fewer total numbers of differentiated cells (B). C,D. NPCs in proliferating media were exposed to METH for $24 \mathrm{hrs}$, followed by culture for 4 days in differentiating conditions. METH does not alter the percentage of cells adopting neuronal, astrocytic, or oligodendrocyte markers. E, F. NPCs were cultured in differentiating conditions for 24 hours, followed by METH treatment for an additional 24 hours. Cells were analyzed 4 days after being placed in differentiating conditions. METH treatment after the onset of differentiation does not significantly affect fate choice (E) or numbers of differentiating cells (F). ${ }^{*} p<0.01$ ANOVA, compared to control.

3-NT antibody, and probed for the presence of PKM2 by Western blot (Figure 6A). METH treatment resulted in a marked increase in nitrotyrosinated PKM2, and this increase was partially blocked by Trolox. We next determined whether METH treatment affected the pyruvate kinase activity of NPC lysates. Indeed, METH treatment reduced PK activity, and this reduction was partially rescued by Trolox (Figure 6B). Thus, METH treatment of NPCs results in nitrotyrosination of PKM2 and a concomitant loss in PK activity.

We next sought to determine whether oxidative and nitrosative stress can directly inhibit activity of PKM2. Treatment with peroxynitrite resulted in nitrotyrosination of recombinant PKM2 and in diminished PK activity (Figure 6C).
Identification of nitrotyrosinated residues of PKM2

We next attempted in vitro studies to determine the possible amino acid sites on PKM2 that can be nitrotyrosinated. In vitro nitrated recombinant PKM2 was analyzed by mass spectrometry along with control protein not exposed to peroxynitrite. The sequence coverage percentages were $76 \%$ and $66 \%$, respectively. All of the tyrosine residues aside from Y161 were detected. Control PK did not contain any nitrated residues while the in vitro nitrated PK contained three nitrotyrosine residues (Table 2). We next modeled the effects of nitrotyrosination on the known crystal structure of PKM2. PKM2 functions as a tetramer, each subunit of which is comprised of three domains (Figure 7A). Of the two nitrotyrosines located in domain A, Tyr 175 is closest to the active site cleft, residing $14.6 \AA$ 


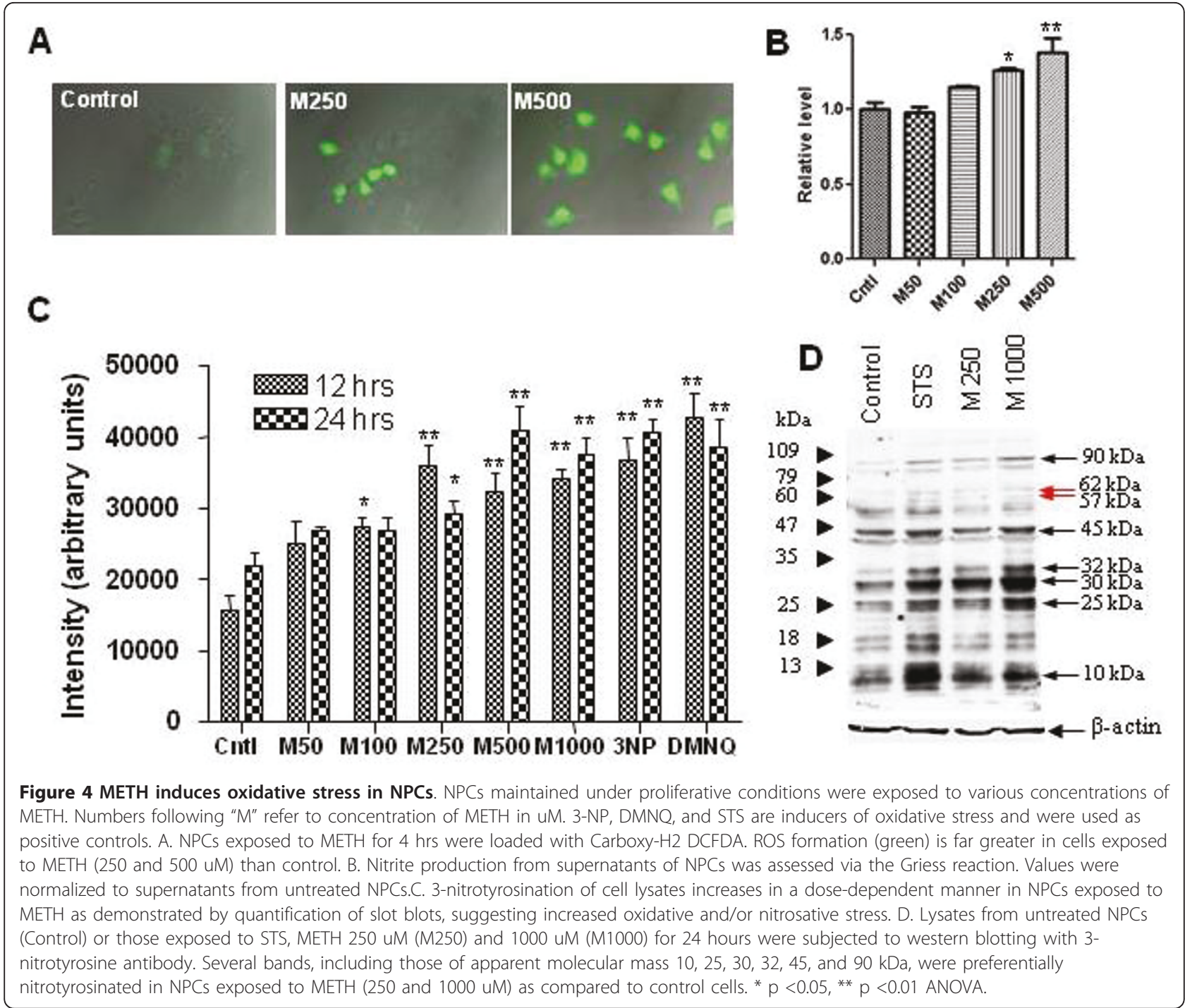

from the $\gamma$-phosphate of the ATP (Figure 7B). The third nitrated tyrosine residue, Tyr 105 , is located at the interface between domains B and C (Figure 7A,C), in close proximity to the allosteric inhibitory site of the enzyme.

\section{Discussion}

We found that METH decreased hippocampal NPC proliferation, increased apoptosis, and led to increased oxidative and nitrosative stress in a well-characterized in vitro system. Further, we identified NPC proteins that were nitrotyrosinated in response to METH, and showed that nitration of one NPC protein implicated in cell proliferation, PKM2, inhibited its activity. Thus, impairment of PKM2 and other NPC proteins via nitration may contribute to impairment of hippocampal neurogenesis in the setting of METH abuse.

It has become increasingly recognized that drugs of abuse can inhibit adult hippocampal neurogenesis, with potentially adverse consequences on regeneration and cognitive function [31,32]. Few studies, however, have focused on how METH may affect neurogenesis. In gerbils, acute METH exposure resulted in a decrease in proliferating NPCs within the hippocampal DG [39]. More recently, short-term administration of stimulant drugs, including METH, resulted in a trend toward decreased hippocampal subgranular zone NPC proliferation in rats [35]. In addition, rats that chronically or regularly self-administered METH over the course of several months also exhibited marked decreases in hippocampal neurogenesis [33]. A recent in vitro study also suggested that METH can impair hippocampal NPC function by inducing apoptosis [36]. Here, we demonstrate that METH inhibits adult hippocampal NPC proliferation, and at higher concentrations impairs survival without affecting neuronal differentiation. METH has recently been found to exert similar effects on proliferation and survival of subventricular zone (SVZ) 

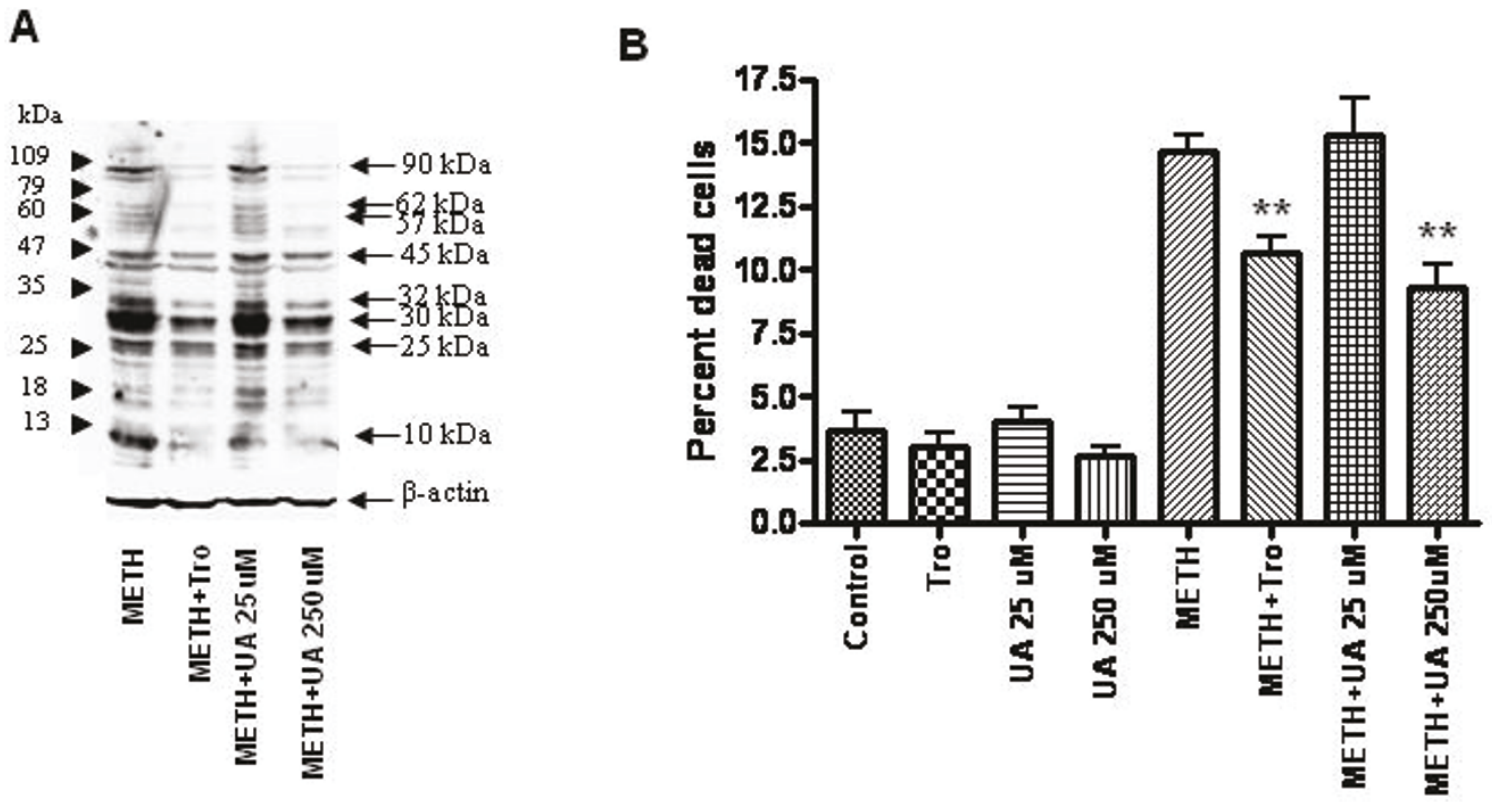

Figure 5 Effects of antioxidants on METH-induced cell death of NPCs. NPCs were preincubated for 2 hrs with either Trolox (10 uM) or uric acid (UA, 25 or $250 \mathrm{uM}$ ), followed by addition of METH (250 uM). Cells were analyzed at 48 hours. (A) Protein lysates were subjected to Western blotting with antibody against 3-nitrotyrosine. Both Trolox and Uric acid markedly decrease nitrotyrosination of a number of NPC proteins. (B). Both Trolox and Uric acid protect against METH-induced NPC death and decrease reactive oxygen species-induced nitrotyrosination $\left(^{* *} p<0.01\right.$, ANOVA).

NPCs [40]. In that study, however, much lower concentrations of METH inhibited neuronal differentiation in SVZ neurospheres. Taken together, these studies suggest that METH affects NPC survival, proliferation, and differentiation in a concentration-dependent manner. Importantly, the lower range of METH concentrations that impaired NPC function in our study are slightly lower than that which causes toxicity to mature neurons, and may be within the dynamic range of concentrations in the brains of tolerant METH abusers during binges [41-43]. Overall, these studies suggest that METH use can result in decreased hippocampal neurogenesis and may contribute to cognitive dysfunction.

An understanding of the cellular and molecular mechanisms by which METH affects NPCs may provide new insights into neurodegeneration and regeneration. A recent in vitro study found that $\mathrm{METH}$, at similar concentrations to those used in this study, can act directly upon NPCs to decrease proliferation, induce oxidative stress, and result in dysregulation of the mitochondrial fission protein DRP1 and concomitant mitochondrial fragmentation [36]. Similarly, in lymphocytes, METH causes increases in intracellular calcium and disruption of the electron transport chain in mitochondria [44]. Oxidative stress has also been implicated in the impairment of hippocampal neurogenesis by alcohol, which is prevented by the synthetic antioxidant ebselen [45]. Surprisingly, in some situations oxidative stress may enhance neurogenesis. Deficiency of the antioxidant enzyme superoxide dismutase 1 (SOD1), for example, results in higher numbers of newly generated hippocampal neurons compared to wild type animals following cranial irradiation, an effect that is potentially mediated through increased oxidative stress [46]. The effects of $\mathrm{NO}$ and nitrosative stress on NPC function are also not fully understood [47]. Several studies suggest that NO donors decrease NPC proliferation and drive differentiation toward the neuronal lineage, while inhibitors of NOS may increase proliferation and decrease differentiation $[48,49]$. A decrease in transcription of the oncogene $\mathrm{N}$-myc may play a role, as its levels correlate with NO-induced changes in NPC proliferation and differentiation [50]. We found striking evidence of both oxidative and nitrosative stress in NPCs upon METH exposure, and this was accompanied by decreased proliferation. Interestingly, we did not note significant effects upon NPC differentiation, nor did we find that METH 
Table 1 Mass spectrometric identification of proteins immunoprecipitated by antibody to 3-nitrotyrosine

\begin{tabular}{|c|c|}
\hline \multicolumn{2}{|l|}{ Heat Shock proteins } \\
\hline & grp75 \\
\hline & Tumor rejection antigen gp96 \\
\hline \multicolumn{2}{|l|}{ Cytoskeletal proteins } \\
\hline & Tropomodulin \\
\hline & Desmoplakin isoform 1,2 \\
\hline \multicolumn{2}{|l|}{ Translation factors } \\
\hline & Aspartyl-tRNA synthetase \\
\hline & Eukaryotic translation elongation factor 1 delta \\
\hline & Ribosomal protein L6 \\
\hline & Acid ribosomal phosphoprotein P0 \\
\hline \multicolumn{2}{|l|}{$\begin{array}{r}\text { Mitochondrial } \\
\text { proteins }\end{array}$} \\
\hline & mitofilin \\
\hline \multicolumn{2}{|l|}{ ER proteins } \\
\hline & ribophorin II \\
\hline & calnexin \\
\hline \multicolumn{2}{|l|}{ Others } \\
\hline & $\begin{array}{l}\text { Procollagen-lysine, } 2 \text { oxoglutarate 5- } \\
\text { dioxygenase } 3\end{array}$ \\
\hline & hnRNP R \\
\hline & Solute carries family 3, member 2 \\
\hline & 82-kD FMRP interacting protein \\
\hline & Histone H1.2 \\
\hline & Pyruvate kinase $\mathrm{M} 2$ \\
\hline
\end{tabular}

affected survival of NPCs that had already begun to differentiate. Thus, METH appears to exert cell-stage specific effects, with proliferating NPCs preferentially affected as compared to differentiating cells.

A major consequence of oxidative and nitrosative stress is protein tyrosine nitration, which results from excessive peroxynitrite formation [51]. Protein tyrosine nitration is a selective process, where only a few proteins get nitrated and only a few tyrosine residues are modified within each protein The nitration of tyrosines does not predictably result in loss of function, as some proteins may exhibit either no measurable change in function or even gain in function upon nitration [51]. In a growing number of neurodegenerative disorders, however, tyrosine nitration has been implicated in disruption of protein function with adverse pathological consequences. In Parkinson's disease, tyrosine nitration can lead to increased aggregation of alpha-synuclein, potentially contributed to the increased formation of Lewy bodies [52]. Similarly, nitration of tau inhibits the ability of monomeric tau to promote microtubule assembly, increases self-aggregation, and facilitates its incorporation into neurofibrillary tangles, one of the pathological hallmarks of Alzheimer's disease $[53,54]$. In addition, the protein L-prostaglandin D synthase (L-PGDS) was found to be highly nitrotyrosinated in the cerebrospinal fluid of HIV-infected individuals as compared to non-HIV-infected individuals, and nitration of the protein diminished its activity [55]. Given the ability of prostaglandins to modulate a wide variety of regulatory pathways, it was hypothesized that nitration of L-PGDS may play a role in the pathogenesis of HIV dementia. Using mass spectrometry, we identified 17 proteins in the 3-NT immunoprecipitate of METH-treated NPCs. These proteins encompass diverse cellular functions, including synthesis of proteins, formation and maintenance of cytoskeletal structure, and energy production. The varied functions of the proteins we identified are consistent with the wide functional range of nitrated proteins identified in neurodegenerative disorders. Interestingly, Gene Ontology analysis indicates that the largest class of nitrated proteins found in in vivo disease models subserve energy metabolism, likely due to involvement of these proteins with oxidative and nitrosative-stress generating redox reactions [56].

We focused on the M2 isoform of pyruvate kinase because of its role in cellular energetics and its expression in proliferating cells. PKM2 is a glycolytic enzyme that converts phosphoenolpyruvate to pyruvate with phosphorylation of ADP to ATP. The M2 isoenzyme PKM2 is expressed in cells with high rates of nucleic acid synthesis, including tumor cells and progenitor cells, and it has been suggested to play an important role in cell proliferation [57]. Recent studies have shown that PKM2 expression is required for cancer metabolism and tumor growth [58]. Interestingly, RNAi approaches to reduce expression of PKM2 inhibit proliferation and tumor growth in a lung cancer xenograft model [59] and in glioma cells [60]. We found that nitration of PKM2 was associated with reduced pyruvate kinase activity and decreased proliferation of NPCs. Thus, post-translational modification of PKM2 by nitration lowers its activity and may be an important mechanism by which METH exerts its inhibitory effects on proliferating NPCs. Notably, nitration may be one of several post-translational modifications that affects PKM2 activity. PKM2 was recently identified as undergoing oxidative modification, as evidenced by increased protein carbonylation, in the brains of patients with mild cognitive impairment (MCI) in a proteomics approach. Interestingly, the increased oxidative modification of PKM2 was associated with reduced enzymatic activity [61].

We found that only three of the nine tyrosine residues of PKM2 were nitrated, consistent with the notion of biological specificity of nitration sites. The crystal structure of pyruvate kinase demonstrates that the three nitrated tyrosines are surface-exposed (Figure 7) [62], an apparent prerequisite to nitration. However, not all exposed 


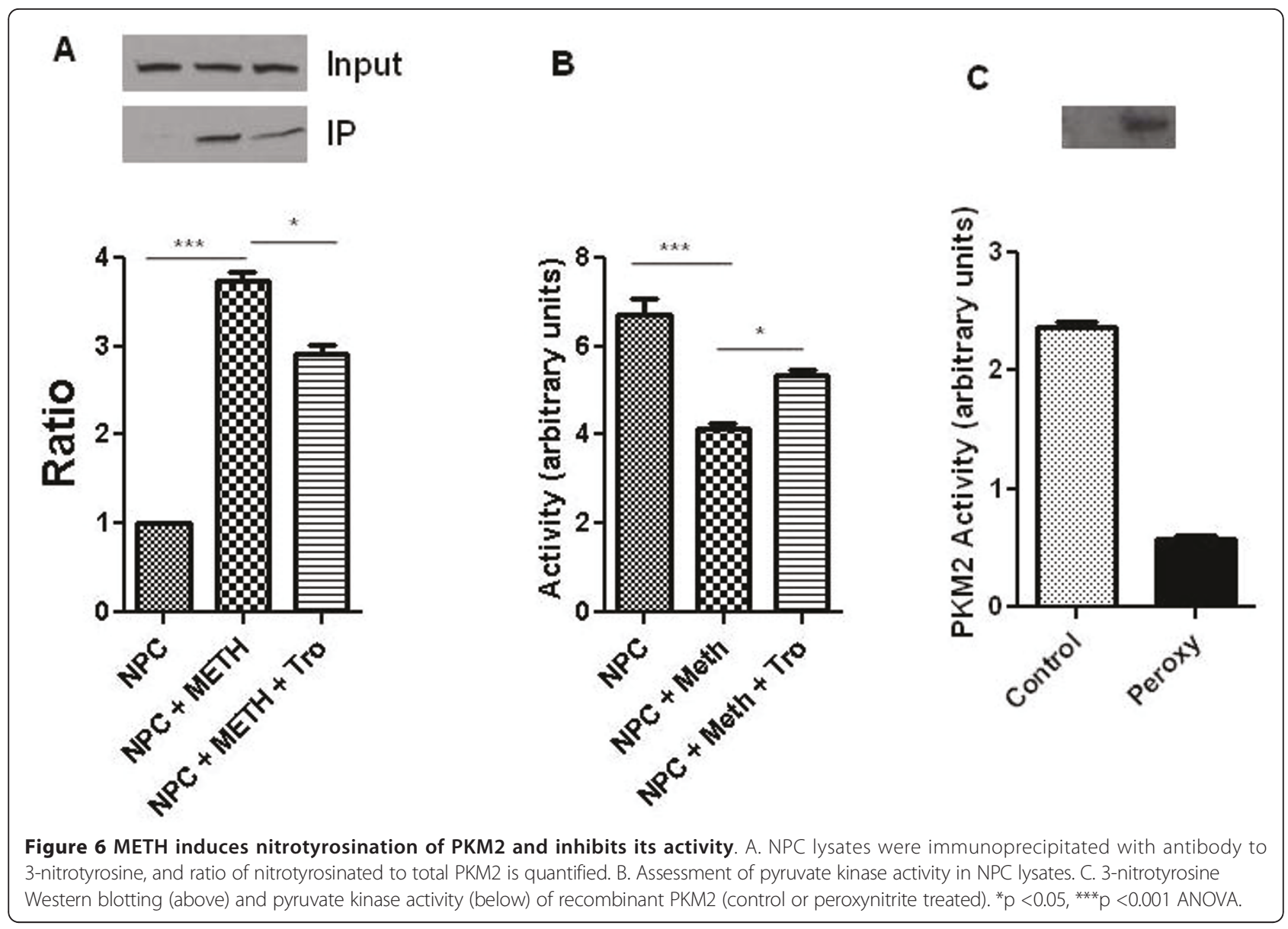

tyrosine residues are capable of being nitrated. Although there is no amino acid consensus sequence that defines sites of tyrosine nitration, the presence of neighboring acidic and turn-inducing amino acids as well as the relative paucity of neighboring cysteines and methionines appears to favor nitration [63]. Examination of the sequences from -5 to +5 amino acids relative to the three nitrated tyrosines in PKM2 reveals the presence of six acidic amino acids, four turn-inducing amino acids, and only one cysteine and one methionine. Thus, the selective nitration of these three PKM2 tyrosines is consistent with previously described findings on the selectivity of protein tyrosine nitration.

Nitrotyrosination of PKM2 may affect both the active site and the allosteric site of the enzyme. The active site of PKM2 is at the cleft between domains A and B of each subunit, and the conformational flexibility of these domains results in the opening and closing of the active site cleft, thereby modulating enzymatic activity [64]. Nitration of Tyr 175 may result in hydrogen bonding to the guanidinium group of Arg 339 in a neighboring subunit (Figure 7B). This is likely to result in changes in mobility or positioning of domain A, thereby modifying enzymatic activity. Notably, a precedent for changes in domain mobility affecting PK enzymatic activity has been established [65]. Nitration of Tyr 105 may affect the allosteric site which, when bound by phenylalanine results in an inhibition of enzymatic activity [66]. At the interface between domains B and C, Tyr 105 is close to the Phe binding site identified in the PKM1 isoform. The nitro group at the benzyl 3 position of Tyr 105 may induce local distortions in a similar manner to the binding of the bulky phenyl group, thus affecting the domain $\mathrm{B} / \mathrm{C}$ interface [66]. Our model of the nitrated tyrosine

Table 2 Summary of the identification of nitrated tyrosines of PKM2 identified by mass spectrometry

\begin{tabular}{cccccc}
\hline Peptide sequence & Charge & Xcorr score & $\mathbf{m} / \mathbf{z}(\mathbf{D a})$ & $\mathbf{M H}+(\mathrm{Da})$ & Delta $\mathbf{M}(\mathrm{ppm})$ \\
\hline ITLDNAY $_{\text {No2 }}$ MEK & 2 & 2.16 & 621.788 & 1242.569 & 1.13 \\
\hline VY $_{\text {No2 }}$ VDDGLISLQVK $_{\text {TATESFASDPILY }}$ No2 $_{\text {RPVAVALDTK }}$ & 2 & 2.16 & 747.394 & 1493.780 & -2.90 \\
\hline
\end{tabular}




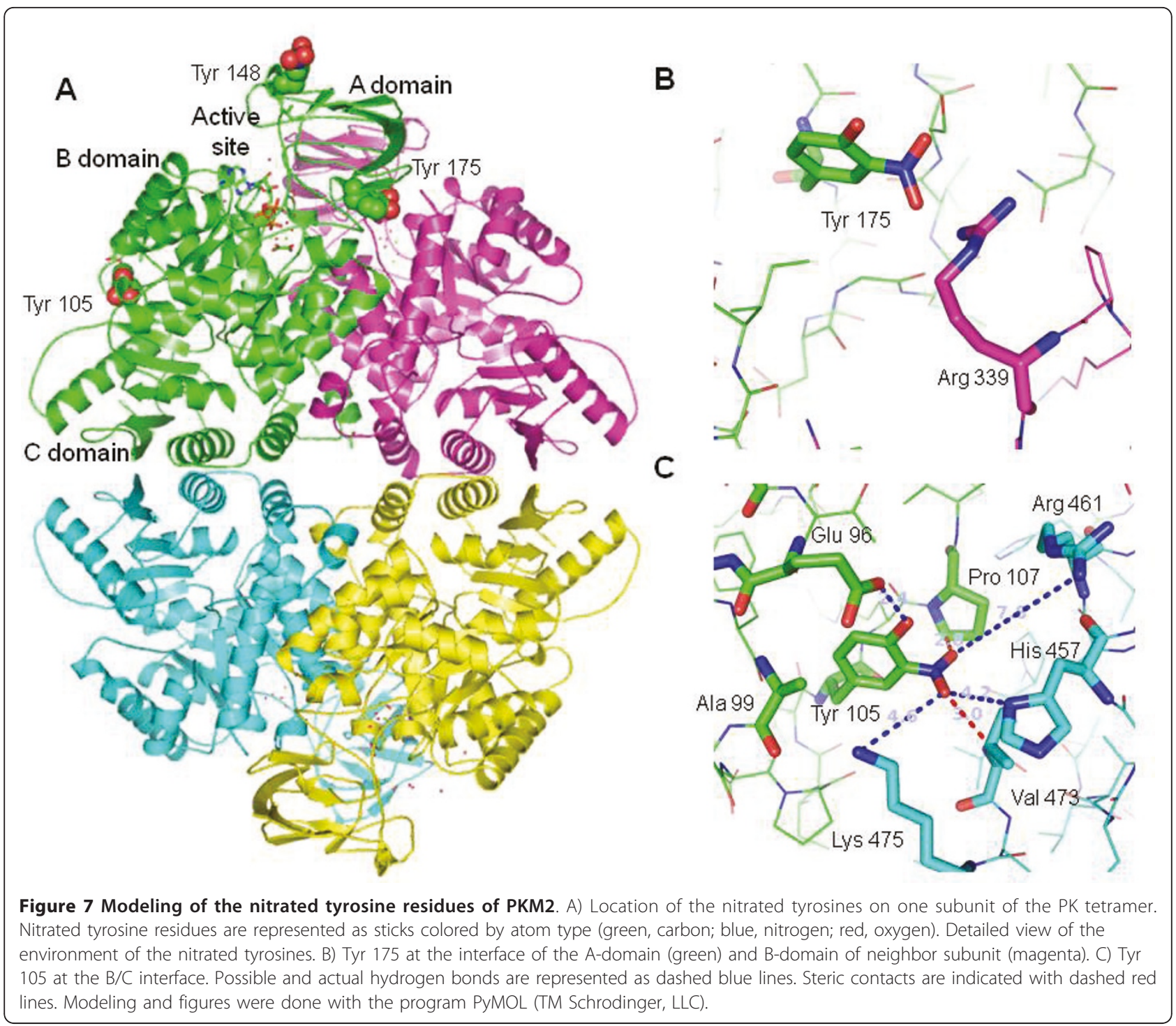

(Figure 7C) shows that the addition of the nitro group to Tyr 105 generates steric conflicts with Pro 107 (B domain) and Val 473 (C domain). In addition, the nitro group may form additional hydrogen bonds with Lys 475, His 457 and Arg 461 of the C domain (Figure 7C), thereby potentially altering the structure of the allosteric site.

\section{Conclusions}

Overall, the observation that hippocampal neurogenesis is impaired by METH has several important implications. Given the emerging evidence suggesting a role for continuous hippocampal neurogenesis in cognitive functioning, a $\mathrm{METH}$-induced reduction in newly generated neurons may impair the maintenance of hippocampal-dependent learning and memory $[19,67,68]$. Indeed, spatial working memory, a task dependent upon hippocampal integrity, is impaired by METH [69]. In addition to countering the deleterious effects of METH on mature neuronal cells, therapeutic strategies may need to be directed at increasing and optimizing neurogenesis in this patient population. More importantly, however, our studies point to a role for METH-induced oxidative and nitrosative stress in impacting NPC proliferation and survival. A better understanding of the effects of nitrotyrosination on NPC protein function will likely yield insights into the pathogenesis of neurodegeneration in the setting of METH abuse and other CNS disorders in which oxidative and nitrosative stress play important roles.

\section{Materials and methods}

\section{Cell culture}

The adult hippocampal NPCs used in this study were clonal stem cells derived from the hippocampus of adult 
Fischer 344 rats, and have been previously shown to fulfill the characteristics of multipotent neural precursor cells both in vitro and in vivo [70]. NPCs were propagated in proliferation media (DMEM/F12 medium containing N2 supplement, L-glutamine [2mM], and FGF-2 [20 ng/mL]), as previously described [70]. For differentiation, NPCs were trypsinized and plated in DMEM/ F12 containing N2 supplement, L-glutamine (2mM), fetal bovine serum (FBS) (1\%; v/v), and retinoic acid (1 $\mu \mathrm{M})$ for up to four days. For most experiments, NPCs were plated directly on laminin-coated 24-well plates to minimize detachment of cells during toxicity assays. Initial plating density was 25,000 cells $/ \mathrm{cm}^{2}$. Cells from passage numbers 15 through 21 were used in all experiments.

\section{Immunocytochemistry and quantification of cell types}

NPCs were fixed with $4 \%(\mathrm{w} / \mathrm{v})$ paraformaldehyde (PFA) and washed with Tris buffered saline (TBS), prior to incubation in blocking solution (TBS with0.25\% (v/v) Triton-X and $0.5 \%(\mathrm{v} / \mathrm{v})$ FBS). Primary antibodies were diluted in blocking solution as follows: anti-bromodeoxyuridine (BrdU) (1:400, rat; Accurate, City, State), anti-nestin (1:1,000, mouse; Sigma, St Louis, MS), anti- $\beta$-tubulin (1:1,000, mouse, BAVCO, City, State), anti-RIP (give full spelling) (1:25, mouse, Hybridoma Bank, City, State), antiglial fibrillary acidic protein (GFAP) $(1: 1,000$, rabbit, Dako, City, State), and incubated with NPCs overnight at $4{ }^{\circ} \mathrm{C}$. The detection of BrdU required treatment of cells with $1 \mathrm{M} \mathrm{HCl}$ at $37^{\circ} \mathrm{C}$ for $30 \mathrm{~min}$ prior to application of the primary antibody. After washing twice with TBS, NPCs were incubated with the appropriate Alexa-fluor conjugated secondary antisera (1:250, Invitrogen), followed by washing and counterstaining with DAPI to label all nuclei. Positive cells were quantified in at least 10 randomly selected fields (20X magnification) in each of at least three wells per condition using a fluorescent microscope, and each experiment was performed in triplicate.

\section{Assays of cell viability and apoptosis}

NPCs maintained under proliferative conditions were exposed to METH (+), which was obtained from the National Institute of Drug Abuse. Cell viability was assessed by exclusion of either trypan blue or 7-amino actinomycin D (7-AAD). Trypan blue was added to a final concentration of $0.2 \%(\mathrm{w} / \mathrm{v})$ to treated cells, followed by direct visualization of cells under a light microscope (give magnification). The percentage of dead cells with blue nuclei were quantified in at least 10 randomly selected fields in each of at least three wells per condition. Alternatively, treated cells were trypsinized, resuspended in phosphate buffered saline, $\mathrm{pH}=7.4$ (PBS), and incubated with 7-AAD (1 ug/mL, Calbiochem, City, State) for 15 minutes, followed by flow cytometric analysis (Becton-Dickinson, City State). The percentage of cells that stained with 7AAD (dead cells) was quantified in at least three separate experiments.

To assess for apoptosis, cells were fixed, washed, and terminal deoxynucleotide nick end labeling (TUNEL) staining was performed using the Promega DeadEnd Fluorescent TUNEL Labeling Kit according to manufacturer's instructions. Cells that had undergone apoptotic DNA fragmentation incorporated FITC-labeled dUTP. TUNEL positive cells were detected by fluorescence microscopy (give magnification).

\section{Detection and inhibition of oxidative stress in NPCs}

Oxidative and nitrosative stress-induction was measured by several methods. Carboxy H2 DCFDA (10 uM, Invitrogen Molecular Probes) is an indicator compound that passively diffuses into cells and is trapped inside upon cleavage by intracellular esterases. Upon interaction with reactive oxygen species, the fluorescent product DCF is formed. NPCs maintained under proliferative conditions were treated with several concentrations of METH for varying time points, followed by incubation with Carboxy $\mathrm{H} 2 \mathrm{DCFDA}$ at $37^{\circ} \mathrm{C}$ for 30 minutes in a $5 \%(\mathrm{v} / \mathrm{v}) \mathrm{CO}_{2}$ incubator. DCF formation was visualized by fluorescence microscopy (give magnification). Nitrite production was measured from the supernatants of METH-treated NPCs using the Promega Griess Reagent System (Cat \# 2930) as per the manufacturer's directions.

Alternatively, the formation of nitrotyrosination adducts on proteins, which represents a common endproduct of several oxidative and nitrosative stress pathways [38] was assessed. NPCs were incubated with either METH or three potent inducers of oxidative stress, staurosporine (0.2 $\mu \mathrm{M}$, Sigma), 3-nitropropionic acid (1 mM, Sigma), or 2,3-dimethoxy-1,4 naphthoquinone (1 mM, Sigma). Cell lysates were collected at varying time points and subjected to either slot-blot analysis (BioRad) or Western blot analysis with antibody to 3-nitrotyrosine (1:1000, Upstate, Charlottesville, VA) and beta-actin (1:5000, Sigma). Blots were developed using the ECL Plus kit (Amersham) followed by quantitative densitometry (Image J, NIH). Each experiment was conducted at least three separate times.

To determine whether antioxidants protect against METH-induced NPC death, NPCs were preincubated for 2 hrs with either Trolox or Uric acid, followed by addition of METH $(250 \mu \mathrm{M})$. Cell lysates were analyzed by Western blot 48 hours later. The concentrations of Trolox $(10 \mu \mathrm{M})$ and uric acid $(25 \mu \mathrm{M}$ and $250 \mu \mathrm{M})$ used were typical of that employed in the literature; of note, levels of uric acid present in the serum of normal humans range from $250 \mu \mathrm{M}$ to $350 \mu \mathrm{M}$ [71,72]. 


\section{Mass spectrometric analysis}

NPC cell lysate was mixed with $3 \mu \mathrm{g}$ of monoclonal antinitrotyrosine antibody (Millipore \#05-233) in an end-overend mixer for 1 hour at room temperature. The mixture was then added to Protein G beads that had been prewashed with PBS, and mixed for 1 hour at room temperature. The beads were then centrifuged and washed extensively, and the protein bound to the beads was eluted with 25 ul of 1x SDS sample buffer. Eluted proteins were separated on NuPage 4-12\% Bio-Tris gels (Invitrogen NP0335) and stained with the SilverQuest Staining kit (Invitrogen \#LC6070). Bands were cut and sliced into $1 \times 1 \mathrm{~mm}$ pieces; then rinsed with methanol and ammonia biocarbonate. After incubation with Trypsin at $37 \mathrm{C}$ overnight, the tryptic peptides were extracted and the supernatant was collected for LCMS-MS analysis using an LTQ Orbitrap (Thermo Fisher). A C18 column (75um id, YMC ODSAQ 5 um particles with $120 \mathrm{~A}$ pore size) was used in $2 \mathrm{D}$ nanoLC with gradient (5-60\% of $0.1 \%$ Fomic acid $/ 90 \%$ acetonitrile) over 30 minutes with a flow rate of 300nL/ min. Data-dependent MS/MS mode was applied and the resulting MS/MS spectra were analyzed using Mascot (Matrix Science, London, UK; version Mascot) and X! Tandem (The GPM, thegpm.org; version 2007.01.01.1). They were set up to search the NCBInr (selected for Rodentia, version 2007.10.15, 137641 entries) with dynamic modification oxidation of Met (+15.995 Da) (peptide and MS/MS tolerance 0.1 and $0.8 \mathrm{Da}$ ).

In vitro nitrated rabbit pyruvate kinase and control rabbit pyruvate kinase were desalted with desalting spin columns (Pierce), dried using a speed vacuum instrument, resuspended in $100 \mathrm{mM}$ ammonium bicarbonate and digested with trypsin $(1: 20, \mathrm{w} / \mathrm{w})$. The peptides were resuspended in $0.1 \%$ formic acid and separated by on-line reversed-phase nanoscale capillary liquid chromatography (Eksigent, Dublin, CA) over a 120 min gradient (Solvent $A, 0.1 \%$ formic acid, solvent $B$ 0.1\% formic acid in $90 \%$ acetonitrile) followed by analysis by ESI-tandem mass spectrometry using a LTQ-Orbitrap mass spectrometer (Thermo Fisher, San Jose, CA). The tandem mass spectra of rabbit pyruvate kinase sample set were extracted and initially analyzed by Thermo Proteome Discoverer 1.1. MS/MS spectra were analyzed using Sequest (Thermo Fisher Scientific, San Jose, CA, USA; version 1.1.0.263) and X! Tandem (The GPM, thegpm. org; version 2007.01.01.1). The rabbit pyruvate kinase database ( 1 entry) was searched with the following parameters: enzyme, trypsin; precursor ion mass tolerance, $0.100 \mathrm{Da}$; fragment ion mass tolerance, $0.800 \mathrm{Da}$; maximum missed cleavage sites, 2 ; and dynamic modifications, oxidation of Met (+15.995 Da) and nitration of Tyr and Trp (44.985 Da). The nitrated peptide hits were manually validated. Scaffold (version Scaffold_3_00_03, Proteome Software Inc., Portland, OR) was used to validate all MS/MS based peptide and protein identifications. Peptide identifications were accepted if they could be established at greater than $95.0 \%$ probability as specified by the Peptide Prophet algorithm [73]Protein identifications were accepted if they could be established at greater than $99.0 \%$ probability and contained at least 2 identified peptides. Protein probabilities were assigned by the Protein Prophet algorithm [74].

\section{Nitrotyrosination and activity of native PKM2 protein}

Peroxynitrite (Cayman Chemicals) was used for nitration of rabbit PKM2 native protein (GenWay Biotech). $89 \mu \mathrm{g}$ of PKM2, $10 \mu \mathrm{l}$ of $10 \mathrm{mM}$ NaHCO3 and $1 \mu \mathrm{l}$ of $\mathrm{OONO}^{-}$ were placed in an eppendorf tube for $10 \mathrm{~min}$ at $\mathrm{RT}$, followed by addition of beta mercaptoethanol to terminate the reaciton. Samples were then analyzed by western blot. Two sets of samples were incubated separately with AntiNitrotyrosine (3-NT; Cat \# 16-163, Millipore) primary antibody (1:500) followed by horseradish peroxidase-conjugated Anti Mouse (1:5000), and with PKM2 primary antibody (1:1000) followed by horseradish peroxidase-conjugated Anti-Rabbit Secondary Antibody (1:5000), and both were detected using ECL Plus.

The Bio Vision Pyruvate Assay Kit (Cat \# K709-100) was used to measure the activity of pyruvate kinase as per manufacturer's instructions.

\section{Acknowledgements}

This work was supported by NIH (K08DA022946) and Howard Hughes Medical Institute to A.V., NIH R01DA024593 to A.N., and NIH (AG024984, NS047344) to H.S.

\section{Author details}

'Department of Neurology, Johns Hopkins University School of Medicine, 600 N. Wolfe St., Baltimore, MD 21287, USA. ${ }^{2}$ Middle Atlantic Mass Spectrometry Laboratory, Johns Hopkins University School of Medicine, 600 N. Wolfe St., Baltimore, MD 21287, USA. ${ }^{3}$ Pharmacology and Molecular Sciences, Johns Hopkins University School of Medicine, 600 N. Wolfe St., Baltimore, MD 21287, USA. ${ }^{4}$ Biophysics and Biophysical Chemistry, Johns Hopkins University School of Medicine, 600 N. Wolfe St., Baltimore, MD 21287, USA. ${ }^{5}$ Institute for Cell Engineering, Johns Hopkins University School of Medicine, 600 N. Wolfe St., Baltimore, MD 21287, USA. ${ }^{6}$ The Solomon H. Snyder Department of Neuroscience, Johns Hopkins University School of Medicine, 600 N. Wolfe St., Baltimore, MD 21287, USA. ${ }^{7}$ National Institutes of Health, Section of Infections of the Nervous Systems, Bldg 10-CRC, Room 7C103; Bethesda, MD 20892.

\section{Authors' contributions}

$A V, L U, Z C, L R, C A$, and $M L$ carried out the experiments. MAB performed the structural modeling. AV, RC, HS, and AN drafted the manuscript. All authors read and approved the final manuscript.

\section{Competing interests}

The authors declare that they have no competing interests.

Received: 13 May 2011 Accepted: 27 June 2011 Published: 27 June 2011

\section{References}

1. Chang L, Ernst T, Speck O, Patel H, DeSilva M, Leonido-Yee M, Miller EN: Perfusion MRI and computerized cognitive test abnormalities in abstinent methamphetamine users. Psychiatry Res 2002, 114:65-79. 
2. Salo R, Nordahl TE, Possin K, Leamon M, Gibson DR, Galloway GP, Flynn NM, Henik A, Pfefferbaum A, Sullivan EV: Preliminary evidence of reduced cognitive inhibition in methamphetamine-dependent individuals. Psychiatry Res 2002, 111:65-75.

3. Simon SL, Dacey J, Glynn S, Rawson R, Ling W: The effect of relapse on cognition in abstinent methamphetamine abusers. J Subst Abuse Treat 2004, 27:59-66.

4. Volkow ND, Chang L, Wang GJ, Fowler JS, Franceschi D, Sedler M, Gatley SJ, Miller E, Hitzemann R, Ding YS, et al: Loss of dopamine transporters in methamphetamine abusers recovers with protracted abstinence. J Neurosci 2001, 24:9414-9418.

5. Kalechstein AD, Newton TF, Green M: Methamphetamine dependence is associated with neurocognitive impairment in the initial phases of abstinence. J Neuropsychiatry Clin Neurosci 2003, 15:215-220.

6. Cadet $\mathrm{J}$, Ordonez SV, Ordonez JV: Methamphetamine induces apoptosis in immortalized neural cells: protection by the proto-oncogene, bcl-2. Synapse 1997, 25:176-184.

7. Deng X, Wang Y, Chou J, Cadet JL: Methamphetamine causes widespread apoptosis in the mouse brain: evidence from using an improved TUNEL histochemical method. Brain Res Mol Brain Res 2001, 93:64-69.

8. Eisch AJ, Schmued LC, Marshall JF: Characterizing cortical neuron injury with Fluoro-Jade labeling after a neurotoxic regimen of methamphetamine. Synapse 1998, 30:329-333.

9. Pu C, Broening HW, Vorhees CV: Effect of methamphetamine on glutamate-positive neurons in the adult and developing rat somatosensory cortex. Synapse 1996, 23:328-334.

10. Stumm G, Schlegel J, Schafer T, Wurz C, Mennel HD, Krieg JC, Vedder H: Amphetamines induce apoptosis and regulation of bcl-x splice variants in neocortical neurons. FASEB J 1999, 13:1065-1072.

11. Schmued LC, Bowyer JF: Methamphetamine exposure can produce neuronal degeneration in mouse hippocampal remnants. Brain Res 1997, 759:135-140.

12. Deng $X$, Cadet JL: Methamphetamine-induced apoptosis is attenuated in the striata of copper-zinc superoxide dismutase transgenic mice. Brain Res Mol Brain Res 2000, 83:121-124.

13. Imam SZ, el-Yazal J, Newport GD, Itzhak Y, Cadet JL, Slikker W Jr, Ali SF: Methamphetamine-induced dopaminergic neurotoxicity: role of peroxynitrite and neuroprotective role of antioxidants and peroxynitrite decomposition catalysts. Ann N Y Acad Sci 2001, 939:366-380.

14. Imam SZ, Newport GD, Itzhak Y, Cadet JL, Islam F, Jr WS, Ali SF: Peroxynitrite plays a role in methamphetamine-induced dopaminergic neurotoxicity: evidence from mice lacking neuronal nitric oxide synthase gene or overexpressing copper-zinc superoxide dismutase. J Neurochem 2001, 76:745-749.

15. Gage FH: Neurogenesis in the adult brain. J Neurosci 2002, 3: 612-613.

16. Ming GL, Song $H$ : Adult neurogenesis in the mammalian central nervous system. Annu Rev Neurosci 2005, 28:223-250

17. Drapeau E, Mayo W, Aurousseau C, Moal ML, Piazza PV, Abrous DN: Spatial memory performances of aged rats in the water maze predict levels of hippocampal neurogenesis. Proc Natl Acad Sci USA 2003, 100:14385-14390.

18. Gourevitch R, Rocher C, Pen GL, Krebs MO, Jay TM: Working memory deficits in adult rats after prenatal disruption of neurogenesis. Behav Pharmacol 2004, 15:287-292.

19. Leuner B, Gould E, Shors TJ: Is there a link between adult neurogenesis and learning? Hippocampus 2006, 16:216-224.

20. Winocur G, Wojtowicz JM, Sekeres M, Snyder JS, Wang S: Inhibition of neurogenesis interferes with hippocampus-dependent memory function. Hippocampus 2006, 16:296-304.

21. Praag Hv, Schinder AF, Christie BR, Toni N, Palmer TD, Gage FH: Functional neurogenesis in the adult hippocampus. Nature 2002, 415:1030-1034.

22. Shors TJ, Miesegaes G, Beylin A, Zhao M, Rydel T, EG: Neurogenesis in the adult is involved in the formation of trace memories. Nature 2001, 410:372-376.

23. Gould E, Beylin A, Tanapat P, Reeves A, Shors TJ: Learning enhances adult neurogenesis in the hippocampal formation. Nat Neurosci 1999, 2:260-265.

24. Nilsson M, Perfilieva E, Johansson U, Orwar O, Eriksson PS: Enriched environment increases neurogenesis in the adult rat dentate gyrus and improves spatial memory. J Neurobiol 1999, 39:569-578.
25. Praag Hv, Christie BR, Sejnowski TJ, Gage FH: Running enhances neurogenesis, learning, and long-term potentiation in mice. Proc Natl Acad Sci USA 1999, 96:13427-13431.

26. Duman RS, Malberg J, Nakagawa S: Regulation of adult neurogenesis by psychotropic drugs and stress. J Pharmacol Exp Ther 2001, 299:401-407.

27. Eisch AJ, Barrot M, Schad CA, Self DW, Nestler EJ: Opiates inhibit neurogenesis in the adult rat hippocampus. Proc Natl Acad Sci USA 2000, 97:7579-7584.

28. Kuhn HG, Dickinson-Anson H, Gage FH: Neurogenesis in the dentate gyrus of the adult rat: age-related decrease of neuronal progenitor proliferation. J Neurosci 1996, 16:2027-2033.

29. Fuchs $E$, Gould E: Mini-review: in vivo neurogenesis in the adult brain: regulation and functional implications. Eur $J$ Neurosci 2000, 12:2211-2214.

30. Parent JM: Injury-induced neurogenesis in the adult mammalian brain. Neuroscientist 2003, 9:261-272.

31. Venkatesan A, Nath A, Ming GL, Song H: Adult hippocampal neurogenesis: regulation by HIV and drugs of abuse. Cell Mol Life Sci 2007, 64(16):2120-2132.

32. Eisch AJ, Harburg GC: Opiates, psychostimulants, and adult hippocampal neurogenesis: Insights for addiction and stem cell biology. Hippocampus 2006, 16(3):271-286.

33. Mandyam CD, Wee S, Crawford EF, Eisch AJ, Richardson HN, Koob GF: Varied access to intravenous methamphetamine self-administration differentially alters adult hippocampal neurogenesis. Biol Psychiatry 2008, 64(11):958-965.

34. Teucherdt-Noordt G, Dawirs RR, Hidebrandt K: Adult treatment with methamphetamine transiently decreases dentate granule cell proliferation in the gerbil hippocampus. J Neural Transm 2000, 107:133-143.

35. Kochman LJ, Fornal CA, Jacobs BL: Suppression of hippocampal cell proliferation by short-term stimulant drug administration in adult rats. Eur J Neurosci 2009, 29(11):2157-2165.

36. Tian C, Murrin LC, Zheng JC: Mitochondrial Fragmentation is Involved in Methamphetamine-Induced Cell Death in Rat Hippocampal Neural Progenitor Cells. PLOS One 2009, 4(5):e5546.

37. Yoneyama M, Kawada K, Shiba T, Ogita K: Endogenous Nitric Oxide Generation Linked to Ryanodine Receptors Activates Cyclic GMP / Protein Kinase G Pathway for Cell Proliferation of Neural Stem/ Progenitor Cells Derived From Embryonic Hippocampus. J Pharmacol Sci 2011, 115:425-432.

38. Radi R: Nitric oxide, oxidants, and protein tyrosine nitration. Proc Natl Acad Sci USA 2004, 101:4003-4008.

39. Teucherdt-Noordt G, Dawirs RR, Hidebrandt K: Adult treatment with methamphetamine transiently decreases dentate granule cell proliferation in the gerbil hippocampus. J Neural Transm 2000, 107:133-143.

40. Bento AR, Baptista S, Malva JO, Silva AP, Agasse F: Methamphetamine exerts toxic effects on subventricular zone stem/progenitor cells and inhibits neuronal differentiation. Rejuvenation Res 14(2):205-214.

41. Baselt RC: Disposition of toxic drugs and chemicals in man Davis, CA: Biomedical Publications; 1982.

42. Cadet JL, Ordonez SV, Ordonez JV: Methamphetamine induces apoptosis in immortalized neural cells: protection by the proto-oncogene, bcl- 2 . Synapse 1997, 25(2):176-184.

43. Cubells JF, Rayport S, Rajendran G, Sulzer D: Methamphetamine neurotoxicity involves vacuolation of endocytic organelles and dopamine-dependent intracellular oxidative stress. J Neurosci 1994, 14(4):2260-2271.

44. Potula R, Hawkins BJ, Cenna JM, Fan S, Dykstra H, Ramirez SH, Morsey B, Brodie MR, Persidsky Y: Methamphetamine causes mitrochondrial oxidative damage in human T lymphocytes leading to functional impairment. J Immunol 185(5):2867-2876.

45. Herrera DG, Yague AG, Johnsen-Soriano S, Bosch-Morell F, ColladoMorente L, Muriach M, Romero FJ, Garcia-Verdugo JM: Selective impairment of hippocampal neurogenesis by chronic alcoholism: protective effects of an antioxidant. Proc Natl Acad Sci USA 2003, 100:7919-7924

46. Fishman K, Baure J, Zou Y, Huang TT, Andres-Mach M, Rola R, Suarez T, Acharya M, Limoli CL, Lamborn KR, et al: Radiation-induced reductions in neurogenesis are ameliorated in mice deficient in CuZnSOD or MnSOD. Free Radic Biol Med 2009, 47(10):1459-1467. 
47. Estrada C, Murillo-Carretero M: Nitric oxide and adult neurogenesis in health and disease. Neuroscientis 2005, 4:294-307.

48. Cheng A, Wang S, Cai J, Rao MS, Mattson MP: Nitric oxide acts in a positive feedback loop with BDNF to regulate neural progenitor cell proliferation and differentiation in the mammalian brain. Dev Biol 2003, 258:319-333.

49. Packer MA, Stasiv Y, Benraiss A, Chmielnicki E, Grinberg A, Westphal H, Goldman SA, Enikolopov G: Nitric oxide negatively regulates mammalian adult neurogenesis. Proc Natl Acad Sci USA 2003, 100:9566-9571.

50. Ciani E, Severi S, Contestabile A, Bartesaghi R, Contestabile A: Nitric oxide negatively regulates proliferation and promotes neuronal differentiation through N-Myc downregulation. J Cell Sci 2004, 117:4727-4737.

51. Souza JM, Peluffo G, Radi R: Protein tyrosine nitration-functional alteration or just a biomarker? Free Radic Biol Med 2008, 45(4):357-366.

52. Gao HM, Kotzbauer PT, Uryu K, Leight S, Trojanowski JQ, Lee VM: Neuroinflammation and oxidation/nitration of alpha-synuclein linked to dopaminergic neurodegeneration. J Neurosci 2008, 28(30):7687-7698.

53. Horiguchi $T$, Uryu $K$, Giasson Bl, Ischiropoulos $H$, LightFoot $R$, Bellmann $C$, Richter-Landsberg C, Lee VM, Trojanowski JQ: Nitration of tau protein is linked to neurodegeneration in tauopathies. Am J Pathol 2003, 163(3):1021-1031.

54. Reynolds MR, Lukas TJ, Berry RW, Binder LI: Peroxynitrite-mediated tau modifications stabilize preformed filaments and destabilize microtubules through distinct mechanisms. Biochemistry 2006, 45(13):4314-4326.

55. Li W, Malpica-Llanos TM, Gundry R, Cotter RJ, Sacktor N, McArthur J, Nath A: Nitrosative stress with HIV dementia causes decreased L-prostaglandin D synthase activity. Neurology 2008, 70(19 Pt 2):1753-1762.

56. Lee JR, Kim JK, Lee SJ, Kim KP: Role of protein tyrosine nitration in neurodegenerative diseases and atherosclerosis. Arch Pharm Res 2009, 32(8):1109-1118

57. Mazurek S, Boschek CB, Hugo F, Eigenbrodt E: Pyruvate kinase type M2 and its role in tumor growth and spreading. Semin Cancer Biol 2005, 15(4):300-308.

58. Christofk HR, Vander Heiden MG, Harris MH, Ramanathan A, Gerszten RE, Wei R, Fleming MD, Schreiber SL, Cantley LC: The M2 splice isoform of pyruvate kinase is important for cancer metabolism and tumour growth. Nature 2008, 452(7184):230-233.

59. Guo W, Zhang Y, Chen T, Wang Y, Xue J, Xiao W, Mo X, Lu Y: Efficacy of RNAi targeting of pyruvate kinase $M 2$ combined with cisplatin in a lung cancer model. J Cancer Res Clin Oncol 2010, 137:65-72.

60. Kefas B, Comeau L, Erdle N, Montgomery E, Amos S, Purow B: Pyruvate kinase $M 2$ is a target of the tumor-suppressive microRNA-326 and regulates the survival of glioma cells. Neuro Oncol 2010, 12(11):1102-1112.

61. Butterfield DA, Poon HF, St Clair D, Keller JN, Pierce WM, Klein JB, Markesbery WR: Redox proteomics identification of oxidatively modified hippocampal proteins in mild cognitive impairment: insights into the development of Alzheimer's disease. Neurobiol Dis 2006, 22(2):223-232.

62. Fenton AW, Johnson TA, Holyoak T: The pyruvate kinase model system, a cautionary tale for the use of osmolyte perturbations to support conformational equilibria in allostery. Protein Sci 19(9):1796-1800.

63. Souza JM, Daikhin E, Yudkoff M, Raman CS, Ischiropoulos H: Factors determining the selectivity of protein tyrosine nitration. Arch Biochem Biophys 1999, 371(2):169-178.

64. Larsen TM, Benning MM, Wesenberg GE, Rayment I, Reed GH: Ligandinduced domain movement in pyruvate kinase: structure of the enzyme from rabbit muscle with $\mathrm{Mg} 2+, \mathrm{K}+$, and L-phospholactate at $2.7 \mathrm{~A}$ resolution. Arch Biochem Biophys 1997, 345(2):199-206.

65. Lee $M H$, Wang $T$, Jang MH, Steiner J, Haughey $N$, Ming GL, Song $H$, Nath A, Venkatesan A: Rescue of adult hippocampal neurogenesis in a mouse model of HIV neurologic disease. Neurobiol Dis 2011, 41:678-687.

66. Williams R, Holyoak T, McDonald G, Gui C, Fenton AW: Differentiating a ligand's chemical requirements for allosteric interactions from those for protein binding. Phenylalanine inhibition of pyruvate kinase. Biochemistry 2006, 45(17):5421-5429.

67. Kee $\mathrm{N}$, Teixeira CM, Wang AH, Frankland PW: Preferential incorporation of adult-generated granule cells into spatial memory networks in the dentate gyrus. Nat Neurosci 2007, 10(3):355-362.

68. Jessberger S, Clark RE, Broadbent NJ, Clemenson GD Jr, Consiglio A, Lie DC, Squire LR, Gage FH: Dentate gyrus-specific knockdown of adult neurogenesis impairs spatial and object recognition memory in adult rats. Learn Mem 2009, 16(2):147-154.
69. Simoes PF, Silva AP, Pereira FC, Marques E, Grade S, Milhazes N, Borges F, Ribeiro CF, Macedo TR: Methamphetamine induces alterations on hippocampal NMDA and AMPA receptor subunit levels and impairs spatial working memory. Neuroscience 2007, 150(2):433-441.

70. Song $H$, Stevens CF, Gage FH: Astroglia induce neurogenesis from adult neural stem cells. Nature 2002, 417:39-44.

71. Aksenov MY, Aksenova MV, Nath A, Ray PD, Mactutus CF, Booze RM: Cocaine-mediated enhancement of Tat toxicity in rat hippocampal cell cultures: the role of oxidative stress and D1 dopamine receptor. Neurotoxicology 2006, 27(2):217-228.

72. Spitsin SV, Scott GS, Mikheeva T, Zborek A, Kean RB, Brimer CM, Koprowski H, Hooper DC: Comparison of uric acid and ascorbic acid in protection against EAE. Free Radic Biol Med 2002, 33:1363-1371.

73. Keller A, Nesvizhskii Al, Kolker E, Aebersold R: Empirical statistical model to estimate the accuracy of peptide identifications made by MS/MS and database search. Anal Chem 2002, 74(20):5383-5392.

74. Nesvizhskii Al, Keller A, Kolker E, Aebersold R: A statistical model for identifying proteins by tandem mass spectrometry. Anal Chem 2003, 75(17):4646-4658.

doi:10.1186/1756-6606-4-28

Cite this article as: Venkatesan et al.: Impairment of adult hippocampal neural progenitor proliferation by methamphetamine: role for nitrotyrosination. Molecular Brain 2011 4:28.

\section{Submit your next manuscript to BioMed Central and take full advantage of:}

- Convenient online submission

- Thorough peer review

- No space constraints or color figure charges

- Immediate publication on acceptance

- Inclusion in PubMed, CAS, Scopus and Google Scholar

- Research which is freely available for redistribution

Submit your manuscript at www.biomedcentral.com/submit
C) Biomed Central 